\title{
Comparative Study of Different Potentiometric Ion-Selective Electrodes for Determination of Certain Polyionic Drugs
}

\author{
A. M. El-Kosasy, Omar Abdel-Aziz, N. Magdy", N. M. El Zahar \\ Pharmaceutical Analytical Chemistry Department, Faculty of Pharmacy, Ain Shams University, \\ Organization of African Unity Street, Abassia, Cairo (11566), Egypt. \\ *E-mail: drnancymagdy@hotmail.com
}

doi: $10.20964 / 110369$

Received: 14 November 2016 / Accepted: 8 March 2016 / Published: 1 April 2016

Selective polyionic electrodes were investigated; using precipitation based technique forming ion-pair complexes between the polycation Polymyxin B (Poly B) and tetrakis (4-chlorophenyl) borate (TpClPB) (sensor 1) and phosphotungstic acid (sensor 2) and ionophore based technique with 2hydroxy propyl beta cyclodextrin (HP $\beta$-CD) (sensors 3 and 4) for determination of Poly B and Cromolyn sodium (CS), respectively. Also an aqueous dispersion of iron oxide magnetic nanoparticles (NPs) was applied with (HP $\beta$-CD) for CS determination (sensor 5). Linear responses within concentration ranges of $10^{-6}$ to $10^{-2}, 10^{-6}$ to $10^{-3}, 10^{-7}$ to $10^{-4}$ and $10^{-6}$ to $10^{-3} \mathrm{~mol} \mathrm{~L}^{-1}$ were achieved, using sensors $1,2,3$ and 4, respectively. On the other hand the sensitivity was increased up to $10^{-8}$ mol $\mathrm{L}^{-1}$ on using sensor 5. Near nernstian slopes of $12.68,53.55,58.93$ and $55.11 \mathrm{mV} /$ decade were observed for sensors 1, 2, 3 and 4, respectively, and an ideal nernstian slope of $59.60 \mathrm{mV} / \mathrm{decade}$ was obtained for sensor 5 . The developed sensors 1, 2, 3 and 4 showed a reasonable selectivity, whereas the selectivity of sensor 5 was the greatest one. The proposed sensors showed successful application for determination of the investigated drugs in pharmaceutical formulations and biological fluids without pretreatment.

Keywords: Ion exchangers, Ionophores, Iron oxide nanoparticles, Ion selective electrodes, Polyions.

\section{$\underline{\text { FULL TEXT }}$}

(C) 2016 The Authors. Published by ESG (www.electrochemsci.org). This article is an open access article distributed under the terms and conditions of the Creative Commons Attribution license (http://creativecommons.org/licenses/by/4.0/). 